\title{
Analysis of Variation of Water Quality in Kelani River, Sri Lanka
}

\author{
N.M.DE.A. Abeysinghe ${ }^{1}$, M.B. Samarakoon ${ }^{2}$

\begin{abstract}
${ }^{1}$ Department of Civil Engineering, Faculty of Engineering, General Sir John Kotelawala Defence University, Sri Lanka Sri Lanka
\end{abstract} \\ ${ }^{2}$ Senior Lecturer, Department of Civil Engineering, Faculty of Engineering, General Sir John Kotelawala Defence University,
}

\begin{abstract}
This research attempted to analyze the variation of surface water quality in Kelani River and finally to create a mathematical model for the Water Quality Index (WQI) by using the data that have been obtained. Kelani River is the second largest river in Sri Lanka while being the most polluted river in the country. It is one of the main sources of drinking water for human beings while being the home for many aquatic species. The ecological aspects of Kelani River are threatened due to the increasing number of industries along both sides of the watershed. The present study is conducted to analyze the water quality in Kelani River using six parameters including $p H$, Turbidity, Temperature, Total phosphate, Nitrates, Dissolved Oxygen (DO), and ultimately finding the Water Quality Index (WQI) by collecting 5 sets of samples from seven locations from March 2017 to August 2017. The highest WQI (72.90) was reported near the Water Treatment Plant in Biyagama, while the lowest WQI (62.98) was achieved near the Water Board Pump in Ambathale. Water quality of five of the samples were in good quality range and the other two samples were in medium quality range. A mathematical model for WQI was created using the above mentioned six water quality parameters.
\end{abstract}

Keywords - Kelani River, Surface Water, Water Quality Index.

\section{INTRODUCTION}

Water is one of the main sources on which our existence and settlement are built upon. Water sources can be found in the forms of rivers, glaciers, rain water, ground water etc. Degradation of these natural water resources and management of available fresh water is becoming more challenging due to various reasons such as Climate change, Geology, topography and soil type. Other than the natural characteristics of these natural water resources, the main factor which disturbs the water quality and the management of these water resources is the anthropogenic influence. As a result it has made the water quality and available fresh water management task more challenging for the water service providers, especially in developing countries. Somehow these activities generate contaminants which finally end up in rivers, streams and oceans through runoff and disposal of effluents. Climate change and land use can be identified as the factors that will directly affect the water bodies available for human and agricultural purposes. Improper land use will lead to soil erosion increasing the mobilization of suspended solids in receiving waters through runoff $[1,2,5]$.

There are 103 natural river basins in Sri Lanka, with a total length of about $4,500 \mathrm{~km}$. However, the increasing demand of urban activities due to the rapid growth of population has been affecting the water quality of these river bodies. It has been identified by several researchers that the decreasing of water quality in rivers is due to point source of pollution such as the direct discharges from various land use types including residential, industrial and agricultural, and also non-point source of pollutants such as urban storm water run-off.

Kelani River is one of the main rivers in Sri Lanka which is considered as the most important river as it covers $80 \%$ of the water supply to Colombo. The starting point of the Kelani River is the Sri Pada mountain range and it travels along the hill country and finally flows in to the ocean at Colombo. Apart from being one of the main sources for potable water, Kelani River is used for transportation, hydropower generation, fisheries, irrigation, sewage disposal and sand extraction. The flow of the river varies between $800-1500 \mathrm{~m}^{3} / \mathrm{s}$ during the monsoon and 20-25 $\mathrm{m}^{3} / \mathrm{s}$ in the dry season, depending on the operation of 3 reservoirs in the catchment. The annual sand extraction is $600-800,000 \mathrm{~m}^{3}$ per year. The sand is mined exclusively by hand. The sand mining causes the river bed to sink by some $10 \mathrm{~cm}$ per year [8].

However the Environmental Foundation Limited (EFL) has stated that Kelani River is the most polluted and threatened river in Sri Lanka due to agricultural runoff and domestic and municipal effluents and the effluents that have been discharged in to the river by the increasing number of industries which are located in the close vicinity of the Kelani River [3].

It has being identified that Kelani River is being polluted day by day due the increasing amount of pollutants that are released into the river. As a result it may reach a point in 
the future where it will no longer be obtainable for the purpose of supplying drinking water. This can be a huge problem as Kelani River plays a vital role in providing drinking water to the Colombo city. So understanding the current status of water quality in Kelani River will be useful for the future.

The aim of this study is to find out how the water quality parameters and the Water Quality Index has been varying along the Kelani River with the influence of the waste disposed by different land use types and finally to create a mathematical model for the Water Quality Index using the collected water quality data.

\section{METHODOLOGY}

\subsection{Study Area}

Samples were collected from seven sampling sites on a stretch of $8 \mathrm{~km}$ along the Kelani River. Fig. 1 shows the selected sampling sites namely,

1 Hela Textiles

2 Water board pump division

3 Pattivila

4 Biyagama Water Treatment Plant

5 Kaduwela Expressway Entrance

6 Lion Brew Factory

7 Malwana

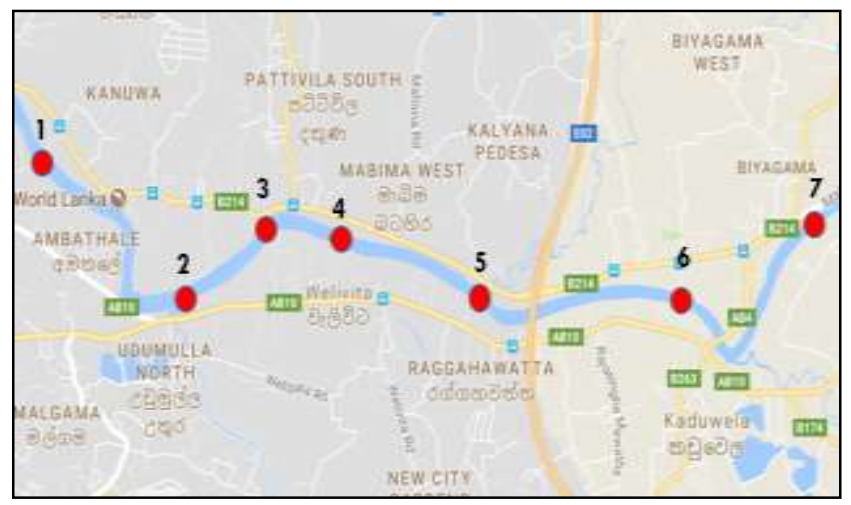

Fig.1: Sampling sites

Five sets of surface water samples were collected at monthly intervals from March, 2017 to August, 2017. Poly ethylene terephthalate (PET) bottles were used to collect the water samples and they were transported to laboratory within 24 hours in a cooler box containing ice.

\subsection{Measurement of Parameters}

Temperature and Dissolved Oxygen (DO) were measured using a EUTECH DO meter, $\mathrm{pH}$ value was measured by a HANNA Combined pH/TEMP/MV meter, Total phosphate and Nitrate was measured using a UV visible spectrophotometer and Turbidity was measured by a HACH Turbidity meter. Model and the serial numbers of these apparatus are given in Table 1.

Table.1: Specifications of apparatus
\begin{tabular}{|l|l|l|}
\hline Apparatus & Model & Serial Number \\
\hline EUTECH DO Meter & DO600 & S/N965992 \\
\hline $\begin{array}{l}\text { HANNA Combined } \\
\text { Digital PH/TEMP/MV } \\
\text { Meter }\end{array}$ & HI2211-02 & S/N08702309 \\
\hline $\begin{array}{l}\text { UV Visible } \\
\text { Spectrophotometer }\end{array}$ & DR6000 & S/N1569293 \\
\hline HACH Turbidity Meter & $2100 \mathrm{~N}$ & $\begin{array}{l}\text { S/N14010C0310 } \\
37\end{array}$ \\
\hline
\end{tabular}

\subsection{Data Analysis}

Microsoft excel 2013 was used to calculate the water quality index value and to interpret the variations of the water quality parameters along the Kelani river.

Water quality Index can be found by using the equation shown in Fig. 2.

Water Quality Index $=\frac{\sum(Q \text { value } x \text { Weighting factor })}{\sum \text { weighning factors }}$

Fig.2: WQI equation

Here, the corresponding q values for the raw data must be taken from the standard q value graphs. Each of the water quality factors is assigned a weighting factor which signifies its importance [6].

A mathematical model for the Water Quality Index was created using The R Project for Statistical Computing with the use of collected water quality data.

\section{RESULTS AND DISCUSSION}

The final results obtained for each and every seven sampling sites are given in Table 2 .

\subsection{Dissolved Oxygen}

The dissolved oxygen (DO) is the amount of oxygen that is dissolved in water. The Dissolved Oxygen (\% sat) values for this study varied between 19.63 and 41.45 . The oxygen dissolved in lakes, rivers, and oceans is very important when it comes to the living of the organisms and creatures in it. The quality of water can be affected, as the amount of dissolved oxygen drops below normal levels in water bodies. As a result the organisms and creatures living in it may die. Moving water contains a large amount of dissolved oxygen while stagnant water has less amount of dissolved oxygen. If the DO concentration is high, then the quality of water can be considered as good [7]. The maximum DO value (41.45) was recorded near the Biyagama Water Treatment Plant while the minimum DO value (19.63) was recorded near the Hela Textiles Company. The standard value for DO (\% sat) is given as 40 or more and here, only one sample has passed that 
value. The variation of DO along the selected area of the Kelani River is given in Fig. 3.

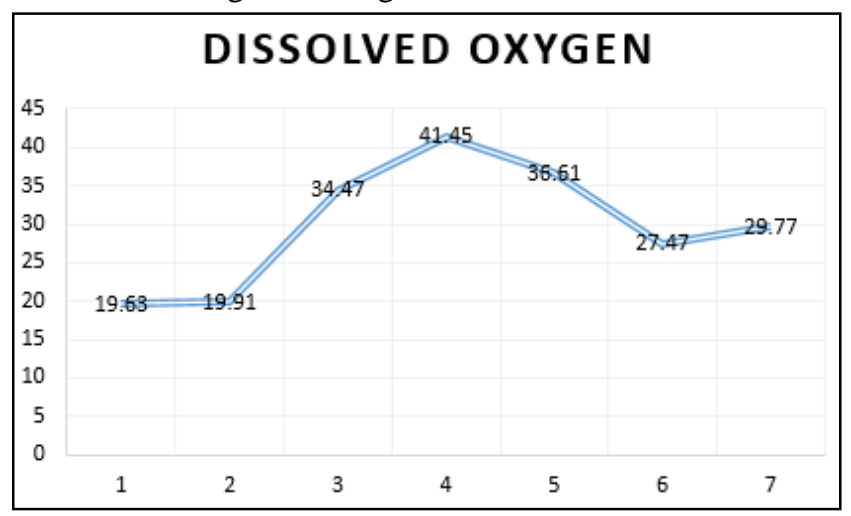

Fig.3: Variation of DO (\%sat)

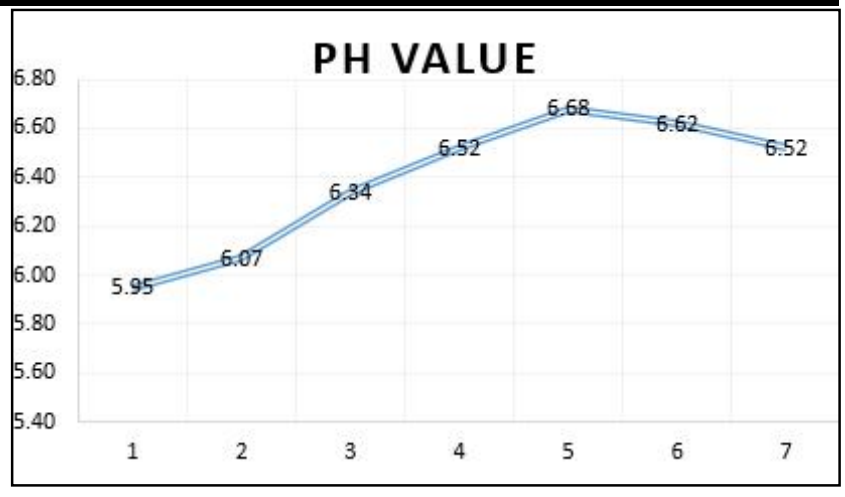

Fig.4: Variation of pH (units)

\section{$3.2 \mathrm{pH}$ value}

$\mathrm{pH}$ is an important parameter for water quality measurement. It is a measure of the acidity or alkalinity of the water. It can also be identified as the measure of hydrogen ion concentration. The $\mathrm{pH}$ scale ranges from 0 to 14. The highest $\mathrm{pH}$ value was recorded near the Kaduwela Expressway Entrance while the lowest $\mathrm{pH}$ value was recorded near the Hela Textiles Company.

Table.2: The average value of each parameter

\begin{tabular}{|c|c|c|c|c|c|c|c|}
\hline Parameter & 1 & 2 & 3 & 4 & 5 & 6 & 7 \\
\hline DO (\% sat) & 19.63 & 19.91 & 34.47 & 41.45 & 36.61 & 27.47 & 29.77 \\
\hline$p H$ & 5.95 & 6.07 & 6.34 & 6.52 & 6.68 & 6.62 & 6.52 \\
\hline Turbidity (NTU) & 8.13 & 4.54 & 9.27 & 9.41 & 6.16 & 11.84 & 9.31 \\
\hline Temperature $\left({ }^{\circ} \mathrm{C}\right)$ & 28.32 & 28.28 & 28.44 & 28.36 & 26.14 & 27.96 & 26.66 \\
\hline Total Phosphate (mg/L) & 0.09 & 0.36 & 0.08 & 0.17 & 0.46 & 0.14 & 0.09 \\
\hline Nitrate $(\mathrm{mg} / \mathrm{L})$ & 0.70 & 1.28 & 0.58 & 0.60 & 0.46 & 0.34 & 0.56 \\
\hline WQI & 65.24 & 62.98 & 70.40 & 72.90 & 70.22 & 70.03 & 70.37 \\
\hline
\end{tabular}

The normal range of $\mathrm{pH}$ for surface water is 6.5 to 8.5 [7]. Here, four of the samples are in the normal range. The variation of $\mathrm{pH}$ values is given in Fig. 4.

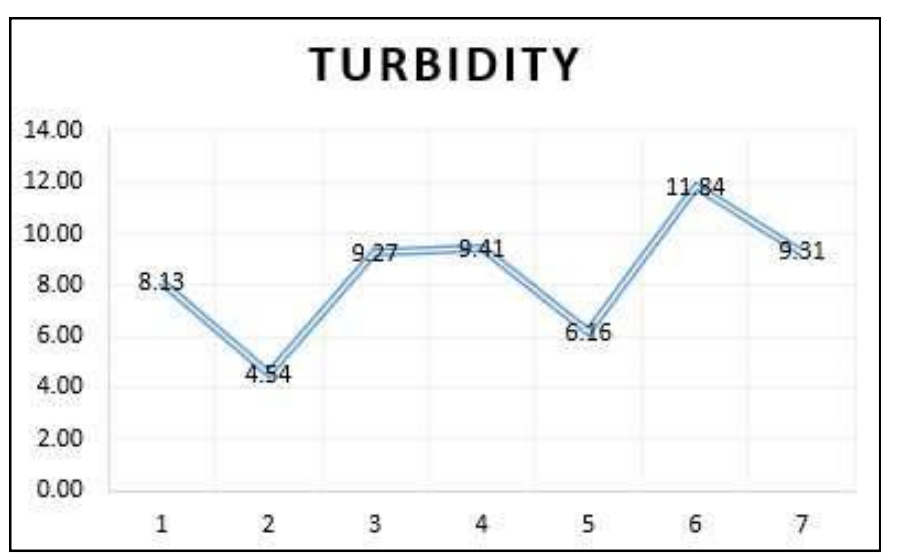

Fig.5: Variation of Turbidity (NTU)
Turbidity is the amount of cloudiness in the water. Water with high turbidity is cloudy, while water with low turbidity is clear. When the turbidity is high, water will be less aesthetically pleasing and also sunlight will warm it more. As a result temperature of the water will be increased. Turbidity is measured by Nephelometric Turbidity Units (NTU). The turbidity of surface water is usually between 1 and 50 [7]. The maximum turbidity value (11.84 NTU) was recorded near the Lion Brew Factory and the minimum turbidity value (4.54 NTU) was recorded near the Water Board Pump Division. The variation of turbidity of the samples is shown in Fig. 5.

\subsection{Temperature}

Temperature is a critical water quality and environmental parameter. It impacts the dissolved oxygen levels, chemical processes, biological process, water density and stratification of a river. The temperature of surface water is usually between $0^{\circ} \mathrm{C}$ and $30^{\circ} \mathrm{C}$ and all the values which were obtained are in this range [7]. The highest temperature $\left(28.44{ }^{\circ} \mathrm{C}\right)$ was recorded near Pattivila area while the lowest temperature $\left(26.14{ }^{\circ} \mathrm{C}\right)$ was recorded near

\subsection{Turbidity}


the Kaduwela Expressway Entrance. Normally the temperature difference of the upstream and the downstream of the river is used for the WQI calculation process. Here it was assumed that the upstream and downstream temperature values are equal, hence there is no temperature difference. The variation of temperature is shown in Fig. 6.

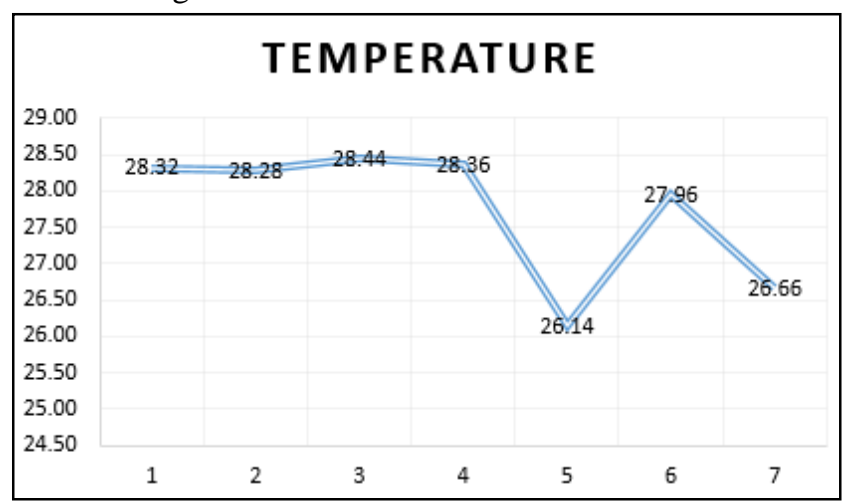

Fig.6: Variation of Temperature $\left({ }^{0} \mathrm{C}\right)$

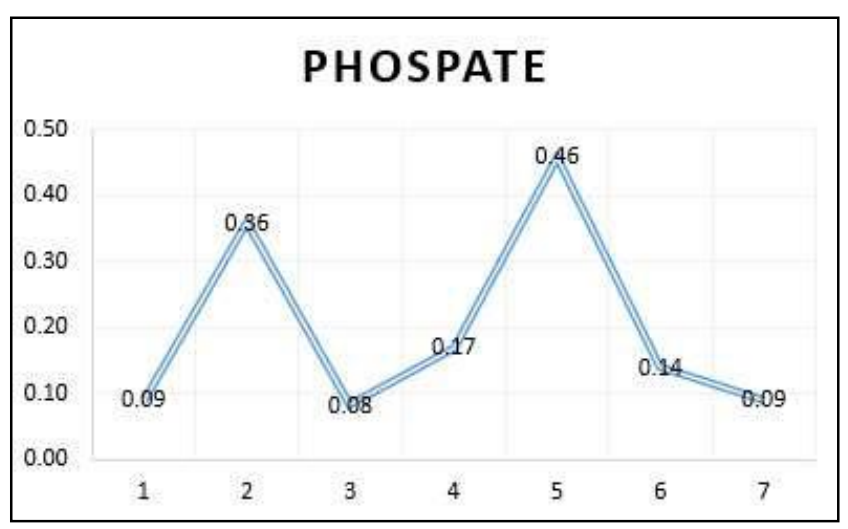

Fig.7: Variation of Total Phosphate ( $\mathrm{mg} / \mathrm{L})$

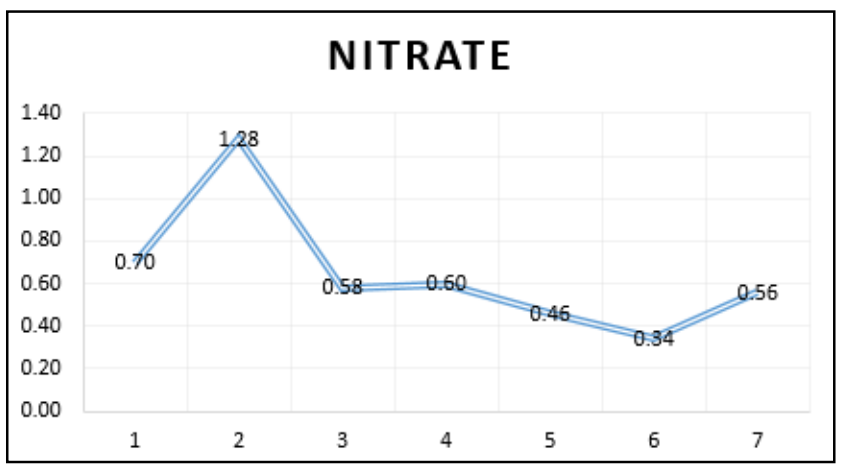

Fig.8: Variation of Nitrate $(\mathrm{mg} / \mathrm{L})$

\subsection{Total Phosphate}

The Phosphate $\mathrm{PO}_{4}^{-3}$ ions can be found in three forms: orthophosphate, metaphosphate (or polyphosphate) and organically bound phosphate. These forms of phosphate occur in living and decaying plant and animal remains, as free ions or weakly chemically bounded in aqueous systems, chemically bonded to sediments and soils, or as mineralized compounds in soil, rocks, and sediments.
Phosphate is a crucial element for plant life but when there is an excessive amount of phosphate in river water, it will speed up the eutrophication process [7]. The maximum amount of phosphate $(0.46 \mathrm{mg} / \mathrm{L})$ was found near the Kaduwela Expressway Entrance while the lowest amount $(0.08 \mathrm{mg} / \mathrm{L})$ was found near Pattivila area. Fig. 7 shows the variation of total phosphate.

\subsection{Nitrate}

Nitrogen is important for all living things as it is a component of protein. Bacteria convert various forms of nitrogen to nitrate $\left(\mathrm{NO}_{3}{ }^{-}\right)$in the soil. Excessive amounts of nitrate can cause an unpleasant condition for the survival of aquatic species and also it will help the algae to grow rapidly. This will create an environment which will speed up the eutrophication process [7]. As shown in Fig. 8, the highest amount of nitrate $(1.28 \mathrm{mg} / \mathrm{L})$ was found near the Water Board Pump Division while the lowest amount $(0.34 \mathrm{mg} / \mathrm{L})$ was found near the Lion Brew Factory.

\subsection{Water Quality Index}

Finally the WQI values were calculated for the seven sampling sites. The overall WQI ranges from 0 to 100 and the quality of water is graded into five classes [6].

- 100-90 Excellent

- $90-70$ Good

- 70-50 Medium

- 50-25 Bad

- 25-0 Very bad

As shown in Fig. 9, five of the samples are in good quality range while two of them are in medium quality range.

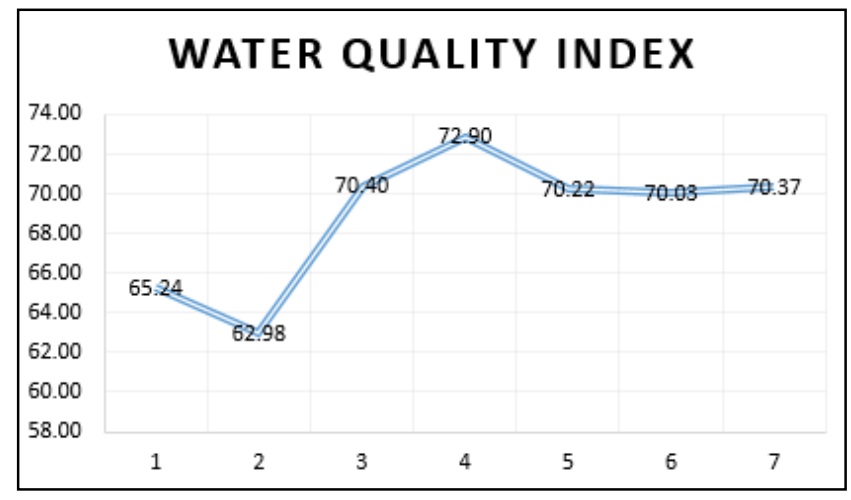

Fig.9: Variation of overall WQI

The highest WQI (72.90) was reported near the Water Treatment Plant in Biyagama, while the lowest WQI (62.98) was achieved near the Water Board Pump in Ambathale.

As the selected stretch of Kelani River has increased number of industries, hotels, restaurants, factories etc. along both sides of the watershed, here it is difficult to expect the quality of water to be in excellent condition. All of these places discharge their waste effluents into Kelani River [4]. 
Fig.10: Mathematical model for WQI

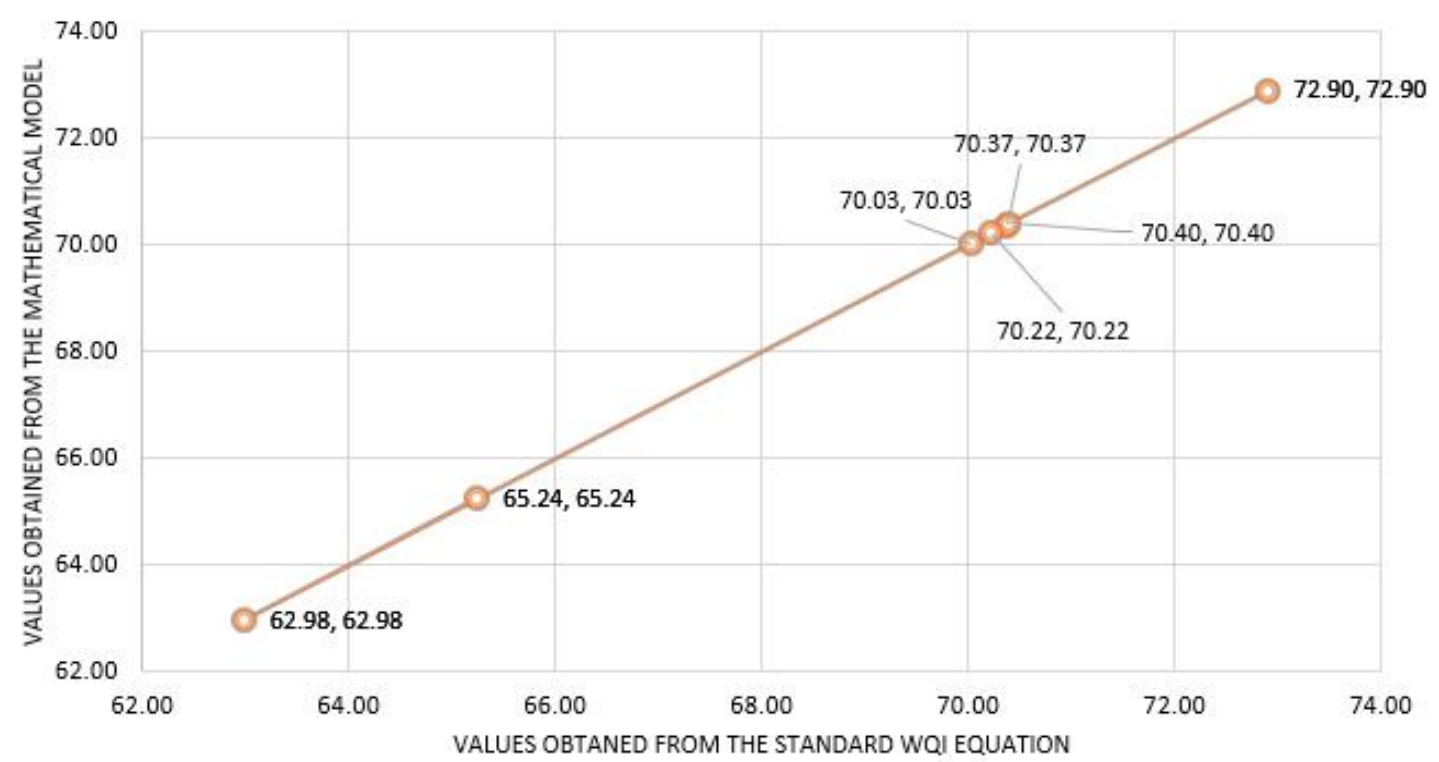

Fig.11: Comparison of values obtained from the mathematical model and the standard WQI equation

\subsection{Mathematical model for Water Quality Index}

The R Project for Statistical Computing was used in order to create a mathematical model for the collected water quality data. Table 2 shows the coefficients which were found for each and every parameter with the use of forward selection method. Intercept was found as 96.4790 .

Table.3: Coefficients for the water quality parameters

\begin{tabular}{|l|l|}
\hline \multicolumn{1}{|c|}{ Parameter } & \multicolumn{1}{c|}{ Coefficient } \\
\hline $\mathrm{DO}$ & 0.3607 \\
\hline $\mathrm{pH}$ & -2.5073 \\
\hline Temperature & -1.1784 \\
\hline Total Phosphate & 1.7175 \\
\hline Nitrate & 1.9844 \\
\hline Turbidity & 1.0368 \\
\hline
\end{tabular}

Fig. 10 shows the ultimate mathematical model for the Water Quality Index. By comparing the values which were obtained using the newly created model and the standard Water Quality Index equation, it can be seen that both the values are same for each and every sampling site. This is illustrated in Fig. 11.

Using this model is much easier than the standard WQI equation, as additional values such as $\mathrm{q}$ values and weighting factors are not considered. The raw data which were collected as inputs for the standard WQI equation can be used with this model.

\section{CONCLUSION}

With the rapid growth of industries along the sides of the Kelani River watershed, the amount of waste effluents that are released into the river has been increased. Understanding the water quality variation in an area like Kaduwela, which is highly populated, will be useful for the implement of pollution mitigation strategies in the future. The highest WQI (72.90) was reported near the Water Treatment Plant in Biyagama, while the lowest WQI (62.98) was achieved near the Water Board Pump in Ambathale. Water quality of five of the samples were in good quality range and the other two samples were in medium quality range.

The use of standard WQI equation can be stressful as there are some additional values to consider apart from the raw data but this newly created mathematical model will be easier to use, as the raw data can be directly entered. This mathematical model can be recommended for use, with the absence of $q$ value graphs and weighting factors.

\section{Acknowledgements}

We take this opportunity to express our gratitude to the Department of Civil Engineering of General Sir John Kotelawala Defence University, Sri Lanka for providing all the laboratory facilities.

\section{REFERENCES}

[1] Chapman, D., 1996. Water Quality Assessments- A Guide to Use of Biota, Sediments and Water in 
Environmental Monitoring. Cambridge: E\&FN Spon, an imprint of Chapman \& Hall.

[2] Goonetilleke, A., Thomas, E., Ginn, S. and Gilbert, D. (2005). Understanding the role of land use in urban stormwater quality management. Journal of Environmental Management, Vol. 74 (No. 1), pp. 3142.

[3] Muiz, S. (2015, September 28). Poisoning Kelani River, Slow and Steady. Retrieved from Daily Mirror: http://www.dailymirror.lk/89167/poisoning-kelaniriver-slow-and-steady

[4] Nizam, I. (2016, April 3). Water Quality Of Kelani River Continues To Decline. Retrieved from The Sunday Leader:http://www.thesundayleader.lk/2016/04/03/w ater-quality-of-kelani-river-continues-to-decline/

[5] Sharma, M.R. and Gupta, A.B., 2004. Prevention and control of pollution in streams of outer Himalayas

[6] Shweta Tyagi, B. S. (2013). Water Quality Assessment in Terms of Water Quality. American Journal of Water Resources, 2013, Vol., 34-38.

[7] The USGS Water Science School. (2016, December 2). Retrieved October 16, 2017, from https://water.usgs.gov/edu/ph.html

[8] Wijesinghe, U. (2010, August 13). Splendor of Sri Lanka. Retrieved October 16, 2017, from https://splendorofsl.wordpress.com/2012/08/13/kelani -river/ 